\title{
COMUNICAÇÕES
}

\section{Scutellonema bradys em Cará-Doce (Dioscorea trifida L.)}

\author{
Ana Cristina Fermino Soares ${ }^{1}$, Marlon da Silva Garrido ${ }^{2}$, João Luiz Coimbra ${ }^{3}$, Nailson Santos de Almeida ${ }^{4}$
}

\begin{abstract}
${ }^{1}$ Professora Titular do Dept. Fitotecnia, Escola de Agronomia da UFBA (AGRUFBA), Cruz das Almas, Bahia, 44380-000 <acsoares@ ufba.br>; ${ }^{2}$ Bolsista Capes, Pós-Graduando em Ciências Agrárias, AGRUFBA <msgarrido@bol.com.br>; ${ }^{3}$ Bolsista CNPq-Recém Doutor, Depto. Fitotecnia, AGRUFBA <joaoluizcoimbra@hotmail.com.br>; ${ }^{4}$ Bolsista PIBIC /FAPESB, AGRUFBA.
\end{abstract}

Data de chegada: 15/09/2004. Aceito para publicação em: 29/04/2005.

1116

A família Dioscoreaceae é constituída de nove gêneros e 600 a 900 espécies, sendo 25 espécies de Dioscorea L. descritas como comestíveis, 15 espécies com uso medicinal e 5 como ornamentais (5). A espécie Dioscorea trifida, conhecida popularmente como cará-doce, possui seu centro de origem no Norte da América do Sul, sendo cultivada em varias regiões do nordeste brasileiro. A planta produz um grupo de pequenas túberas com 15-20 $\mathrm{cm}$ de comprimento, pesando $80-150 \mathrm{~g}$, com massa feculenta branca, amarela, rosa ou púrpura (6). Dentre as nematoses, a casca preta causada pelo nematóide Scutellonema bradys (Steiner \& Le Hew) Andrassey é a principal doença que ataca as espécies do gênero Dioscorea. Este patógeno se aloja na periferia das túberas não se aprofundando mais que $5 \mathrm{~cm}$ (4). Dentre as espécies do gênero Dioscorea utilizadas para a alimentação, apenas o cará São Tome (Dioscorea alata $\mathrm{L}$.) é citado como imune à casca preta (3). No presente trabalho, fez-se a descrição do sintoma de casca preta e a identificação do fitonematóide associado a esse sintoma em túberas de cará-doce ( $D$. trifida L.).

Túberas de $D$. trifida foram coletadas no município de Maragojipe - Bahia. As túberas foram lavadas com água corrente e cortadas no sentido vertical para a aferição da espessura das lesões na polpa, a largura e a profundidade das rachaduras na epiderme das túberas, com o auxilio de um paquímetro. Posteriormente, foram retiradas as cascas das túberas, estas foram pesadas em balança digital de três dígitos e foi feita a extração dos nematóides, utilizando-se a técnica do liquidificador aliada à centrifugação em solução de sacarose mais caolim (2). Para a quantificação dos nematóides infectando as túberas, colocou-se a suspensão de nematóides numa Lâmina de Peters e fez-se a contagem destes com o auxílio de um microscópio óptico. Para a identificação do fitonematóide, foram montadas lâminas semipermanentes, usando-se como líquido de montagem a formalina a $3 \%$ e vedação com permount.

As túberas avaliadas apresentavam-se infectadas apenas pelo nematóide S. bradys (Figura 2). Foi observado um número elevado desse fitonematóide, $2930( \pm 680)$ por $10 \mathrm{~g}$ de túbera (casca + camada superficial da polpa). Os sintomas externos nas túberas são muito semelhantes aos verificados em túberas de inhame da costa (Dioscorea cayennensis L.), atacados por Pratylenchus coffeae (Zimmermann) Filipjev \& Schuurmans Stekhoven, que apresentam rachaduras profundas na epiderme e elevada perda de água das túberas, causando murcha das mesmas (1). As rachaduras nas túberas de cará-doce (Figura $1 \mathrm{C}$ ) apresentam profundidade de $0,82 \mathrm{~mm}( \pm 0,39)$ e largura de $3,51 \mathrm{~mm}( \pm 1,28)$. As necroses na polpa (Figura 1A e D) apresentam profundidade de $1,53 \mathrm{~mm}( \pm 0,48)$, deixando as túberas com aspecto inadequado para a comercialização (Figura 1). A planta não apresenta sintomas típicos de nematose na parte aérea. Esse é o primeiro relato de Scutellonema bradys parasitando túberas de Dioscorea trifi$d a$ L. no Brasil.

\section{AGRADECIMENTOS}

Os autores agradecem à Fundação de Amparo à Pesquisa do Estado da Bahia- FAPESB, pelo auxílio financeiro.

\section{REFERÊNCIAS BIBLIOGRÁFICAS}

1. Acosta, N.; Ayala, A. Pathogenicity of Pratylenchus coffeae, Scutellonema bradys, Meloidogyne incognita and Rotylenchulus reniformis on Dioscorea rotundata. Journal of Nematology, Jay, v.7, n.1, p. 1-5, 1975.

2. Coolen, W.A.; D'Herde, C.J. A method for the quantitative extraction of nematodes from plant tissue. Ghent: State Agricultural Research Center, 1977. 77p.

3. Moura, R. M.; Pedrosa, E.M.R.; Guimarães, L.M.P. Novos dados sobre a etiologia da casca preta do inhame no Nordeste do Brasil. Nematologia Brasileira. Brasília, v. 25, n.2, p.235-237, 2001.

4. Moura, R. M. Doenças do Inhame. In: Kimati, H. et al. (Ed). Manual de fitopatologia. 3. ed. São Paulo: Agronômica Ceres, 1997. v. 2, p.463-471.

5. Pedralli, G. Dioscoreaceae e Araceae: aspecto taxonômicos, etnobotânicos e espécies nativas com potencial para melhoramento genético. In: Santos, E. S. (Ed). Simpósio Nacional sobre as Culturas do Inhame e do Taro, 2002, João Pessoa. p.37-53.

6. Santos, E. S. dos. Inhame (Dioscorea spp.) aspectos básicos da cultura. João Pessoa: EMEPA-PB, Sebrae, $1^{a}$ ed., 1996. $158 \mathrm{p}$. 


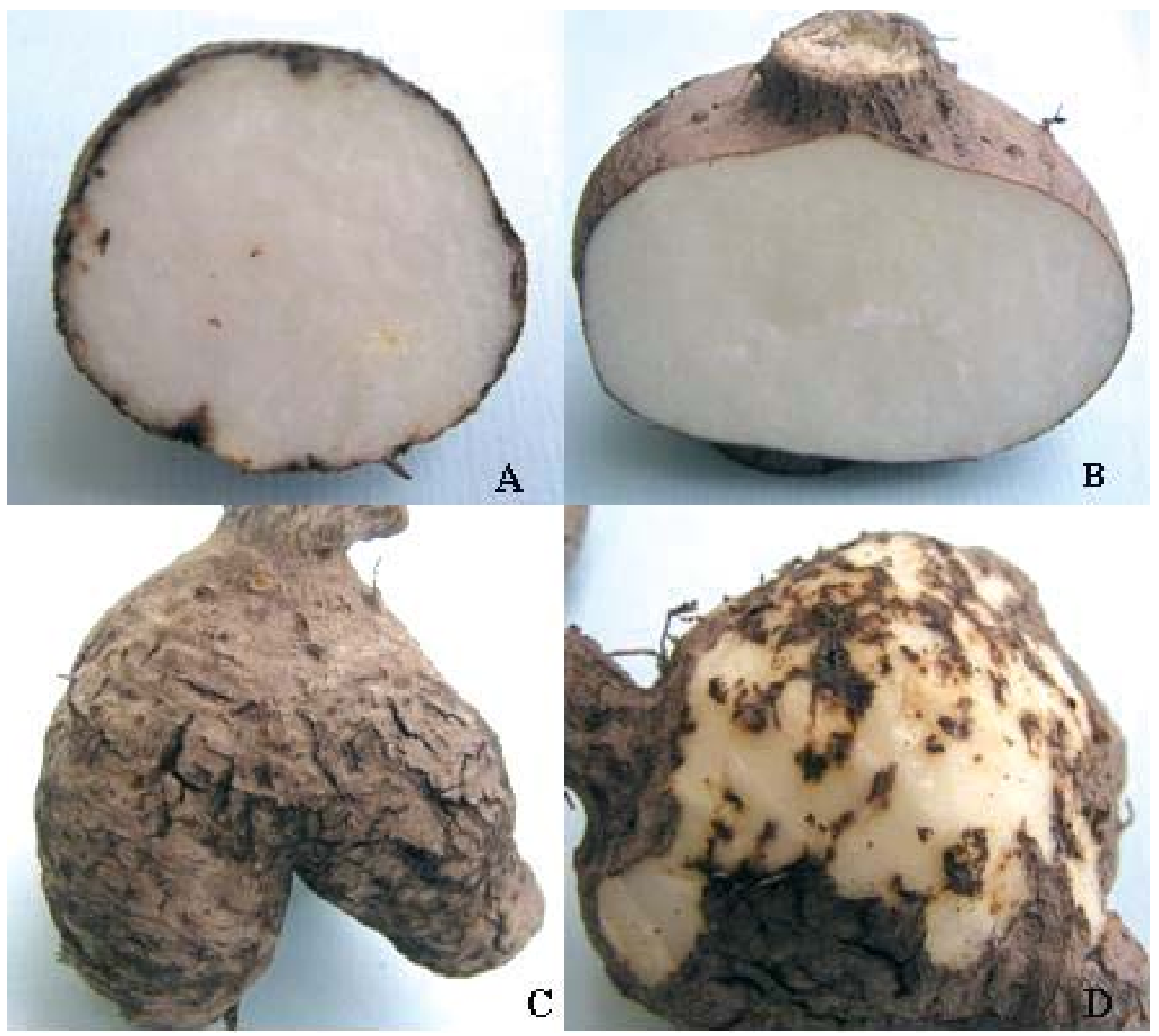

Figura 1. Cará-doce (Dioscorea trifida L.) com sintomas causados pelo fitonematóide Scutellonema bradys. Necrose na polpa (A e D), túbera sadia (B) e túbera com rachaduras (C).

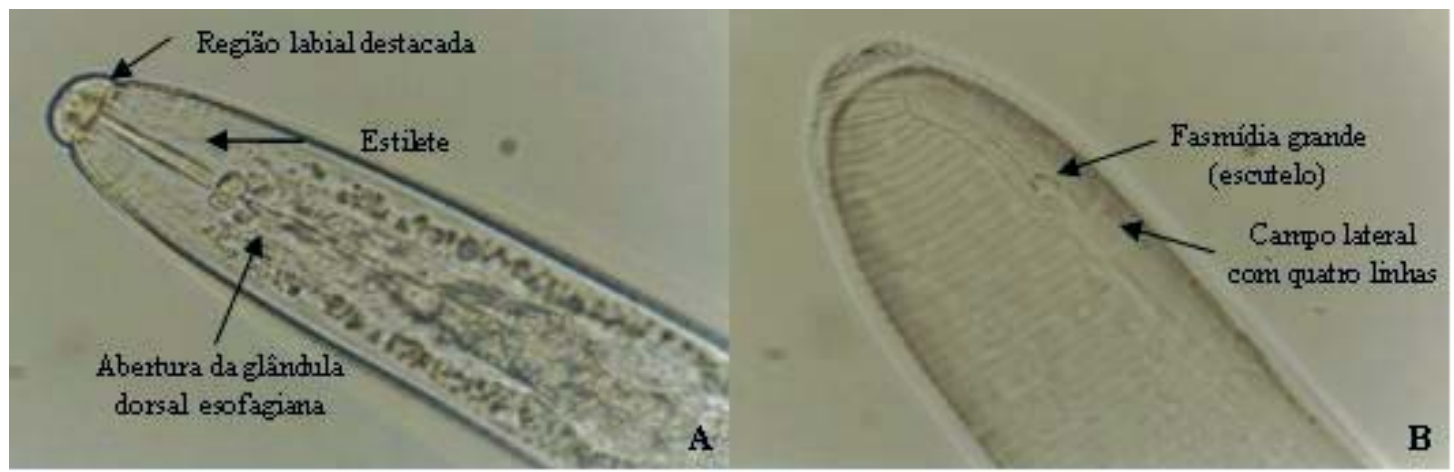

Figura 2. Fotomicrografia de Scutellonema bradys. Região anterior (A) e região posterior (B), mostrando estruturas de importância taxonômica. 